ИЗВЕСТИЯ АҚАДЕМИИ НАУК ЭСТОНСКОИ ССР. ТОМ 30 Химия. 1981, № 1

\title{
ЭФФЕКТЫ ВЗАИМНОГО ВЛИЯНИЯ ПРИ СООКИСЛЕНИИ ФЕНОЛОВ, ХИНОНА И БЕНЗ(а)ПИРЕНА
}

\author{
(Представил М. Губергриц)
}

В состав вредных компонентов сточных вод топливно-химической и других видов промышленности входят фенолы и полициклические арены, которые обладают канцерогенными, канцерогенно-промоторными или токсическими свойствами. Для обезвреживания таких вод часто применяются окислительные методы очистки. Чтобы повысить эффективность этих методов, необходимы соответствующие данные о кинетике окислительного превращения вредных компонентов. Если закономерности деградации в различных процессах окисления у фенолов изучелы подробно как с теоретической, так и с прикладной точки зрения, то $\mathbf{y}$ канцерогенных полициклических аренов в основном исследован только их метаболизм. Несмотря на возможное взаимное действие аренов и фенолов в процессе окисления, данные о совместном их окислении почти отсутствуют.

Целью настоящего исследования явилось изучение кинетики окислительного превращения фенола, пирокатехина, гидрохинона и хинона между собой и с одним типичным канцерогенным ареном - бенз(а) пиреном (БП) - для получения исходных данных по прогнозированию эффективности очистки от них сточных вод.

\section{Методика и объекты исследования}

В эксперименте использовались препараты фирмы «Flucka AG» (Швейцария): фенол (1-гидроксибензол), пирокатехин (1,2-дигидроксибензол), гидрохинон (1,4-дигидроксибензол), хинон (1,4-бензохинон) х. ч., дополнительно очищенные сублимацией. Содержание БП в растворе определялось спектрофотометрически по поглощению при 385 нм с учетом фона, содержание фенола [ $\left.{ }^{1}\right]$, пирокатехина [ $\left.{ }^{1}\right]$ и хинона $\left[{ }^{2}\right]-$ колориметрически по реакции с 4-аминоантипирином.

Окисление инициировалось полихроматическим излучением ртутной лампы СВД-120 в диапазоне выше $200-210 \mathrm{\mu \mu}$ и с максимумом испускания при $365 \mathrm{m \mu}\left[{ }^{3}\right]$. Эксперимент проводился при $20 \pm 1^{\circ} \mathrm{C}$ и $\mathrm{pH} 7$ в $96 \%$-ном водном этаноле и с реагентами $0,5,1,2,3,5,7,5$ и $10 \cdot 10^{-4}$ моль $\cdot \Omega^{-1}$ в колбе Әрленмейера емкостью 100 мл с пришлифованной кварцевой пробкой и с магнитным перемешиванием в условиях барботажа кислородом. 


\section{Кинетические закономерности окисления}

Для изученных реакций наблюдалось в основном линейное снижение концентрации реагента во времени (рис. 1). Следовательно, временной порядок окисления фенолов, хинона и БП нулевой, и подходящим кинетическим показателем реакции является ее стационарная скорость $v$. Скорость реакции определялась интегральным способом [ $\left.{ }^{4}\right]$ с помощью метода наименьших квадратов на вычислительном устройстве 15 ВСМ-5. Концентрационный (истинный) порядок реакции окисления, рассчитанный по [4], для всех реагентов является дробной величиной (табл. 1), что, на наш взгляд, обусловлено сложным механизмом изученного процесса: часть фенолов и БП разлагаются в результате непосредственного взаимодействия кванта света с молекулой реагента, а значительная часть исходного вещества расходуется в результате взаимодействия с промежуточными продуктами первичного фотохимического превращения растворителя или растворенного кислорода [5].

Судя по скорости реакции (табл. 1), а также по временам полураспада $\left(\tau_{1 / 2}\right)$, самая высокая скорость окисления была у бензохинона $\left(\tau_{1 / 2}=1,2-4\right.$ мин $)$, в 5-10 раз медленнее окислялись пирокатехин и гидроксибензол $\left(\tau_{1 / 2}=20-40\right.$ и $50-110$ мин соответственно). Ввиду почти полной локализации заряда в молекуле БП скорость окисления у него была в $100-300$ раз ниже, чем у хинона $\left(\tau_{1 / 2}=240-1300\right.$ мин $)$.

Известно, что пирокатехин и хинон являются классическими про-

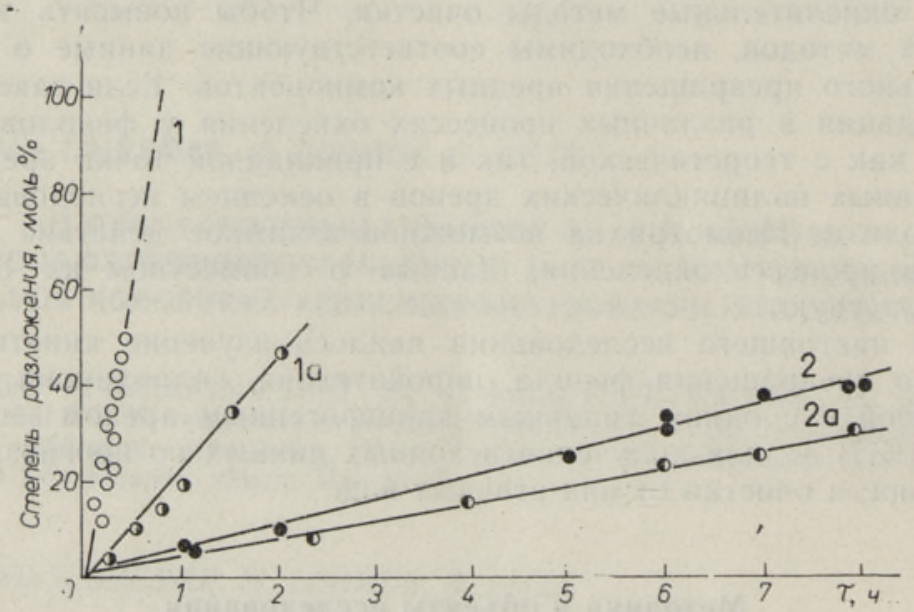

Рис. 1. Кинетика окисления пирокатехина $3 \cdot 10^{-4}$ моль/л (1) и бенз (а) пирена $5 \cdot 10^{-4}$ моль/ $/ \Omega$ (2) раздельно и в смеси (a).

Таблица 1

Скорость $(v)$ фотоинициированного окисления фенолов, хинона и бенз(а)пирена в $96 \%$-ном этаноле при $20^{\circ} \mathrm{C}$ и рН 7

\begin{tabular}{|c|c|c|c|c|}
\hline \multirow[t]{2}{*}{ Реагент } & \multicolumn{3}{|c|}{$\begin{array}{c}v \cdot 10^{-7} \text { моль } \cdot \Omega^{-1} \cdot c^{-1} \text { при исходной концентрации } \\
10^{-4} \text { моль } \cdot \Omega^{-1}\end{array}$} & \multirow{2}{*}{$\begin{array}{c}\text { Концентрацион- } \\
\text { ный порядок } \\
\text { реакции, } n_{c}\end{array}$} \\
\hline & 1 & 5 & 10 & \\
\hline Фенол & $0,53 \pm 0,02$ & 1,50 & $2,00 \pm 0,25$ & 0,6 \\
\hline Пирокатехин & $0,46 \pm 0,03$ & $1,74 \pm 0,11$ & $2,22 \pm 0,21$ & $0,67 \pm 0,07$ \\
\hline Хинон & $5,18 \pm 0,19$ & $14,97 \pm 0,5$ & $21,3 \pm 1,3$ & $0,62 \pm 0,02$ \\
\hline Бенз (a)пирен & $0,036 \pm 0,0015$ & $0,051 \pm 0,002$ & $0,068 \pm 0,007$ & $0,28 \pm 0,01$ \\
\hline
\end{tabular}




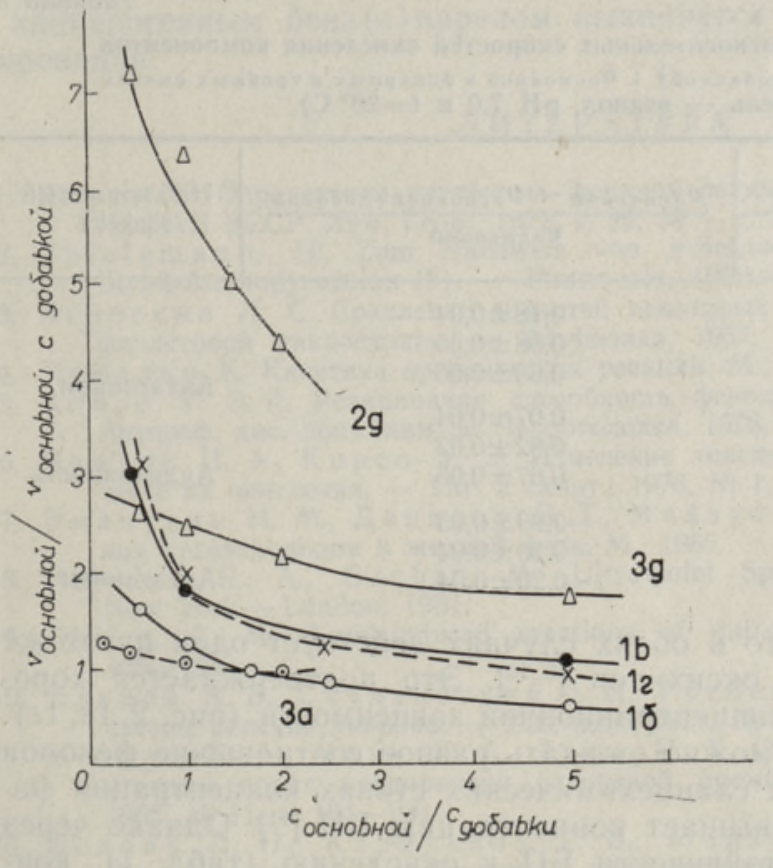

Рис. 2. Влияние концентрации добавки $(a$ - фенола, 6 - пирокатехина, 8 гидрохинона, 2 - хинона, $\partial-6 е н з($ a)пирена) на относительную скорость окисления фенола (1), пирокатехина (2) и хинона (3); $t=$ $=20^{\circ} \mathrm{C}, \mathrm{pH} 7$.

дуктами окисления фенола. Учитывая тот факт, что токсичность пирокатехина, гидрохинона и особенно хинона относительно теплокровных животных во много раз превышает токсичность исходного фенола [ $\left.{ }^{6}\right]$, представляет интерес выяснить возможность их накопления при окислении гидроксибензола. Судя по скорости превращения (табл. 1), можно предположить, что накапливаться в растворе, особенно при высоких концентрациях фенола, может пирокатехин, а скорость расходования бензохинона на два порядка выше скорости его образования.

Хорошо известно, что многие фенолы являются ингибиторами свободнорадикальных реакций окисления [7], поэтому следует ожидать протекания конкурентных процессов при их совместном окислении, что и подтверждается экспериментом (рис. 2; табл. 2). Скорость окисления основного реагента снижается тем больше, чем выше концентрация (молярная доля) добавки. Особенно сильно БП уменьшает скорость окисления фенолов и хинона (рис. $2,2 \partial$ и $3 \partial$ ). Одной из причин такого явления может быть эффект экранирования, наблюдаемый в результате поглощения излучения добавкой. Так, например, коэффициент молярной экстинкции у БП в области $260-270$ нм в $20-40$ раз больше, чем у фенолов [8]. Кроме того, двухатомные фенолы и хинон окисляются с большей скоростью, чем гидроксибензол. Вероятно, за ингибирующее действие двухатомных фенолов и хинона могут быть ответственными продукты их окисления.

Сходство во влиянии гидрохинона и хинона на окисление фенола

таблица 2

Влияние добавки на скорость фотоинициированного окисления бенз(а)пирена в $96 \%$-ном этаноле $\left(t=20^{\circ} \mathrm{C}, \mathrm{pH} 7\right)$

\begin{tabular}{|c|c|c|c|c|c|c|c|}
\hline \multirow{2}{*}{ Добавка } & \multicolumn{4}{|c|}{$v_{\text {БП }} / v_{\text {БП+добавка }}$ при концентрационном } & \multicolumn{3}{|c|}{ м соотношении $c_{\text {БП }} / c_{\text {добавка }}$} \\
\hline & 0,20 & 0,33 & 0,50 & 1,0 & 1,7 & 2,0 & 5,0 \\
\hline $\begin{array}{l}\text { Фенол } \\
\text { Хинон } \\
\text { Пирока- }\end{array}$ & $0,3 \overline{ \pm} 0,04$ & $\underline{0,64}$ & $\begin{array}{l}0,65 \pm 0,14 \\
0,53 \pm 0,04\end{array}$ & $\begin{array}{c}0,39 \\
0,66 \pm 0,05\end{array}$ & - & $\begin{array}{l}1,17 \pm 0,14 \\
0,84 \pm 0,06\end{array}$ & - \\
\hline техин & - & - & $1,11 \pm 0,07$ & $1,05 \pm 0,14$ & $1,06 \pm 0,14$ & - & $0,94 \pm 0,09$ \\
\hline
\end{tabular}


Таблица 3

Соотношение изменения относительных скоростей окисления компонентов

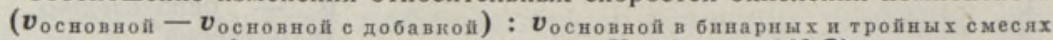
(растворитель - этанол, рН 7,0 и $t=20^{\circ} \mathrm{C}$ )

\begin{tabular}{|c|c|c|c|}
\hline \multicolumn{2}{|c|}{$\begin{array}{c}\text { Реагент при концентрации } \\
1 \cdot 10^{-4} \text { моль } \Omega^{-1}\end{array}$} & \multirow{2}{*}{$\frac{\boldsymbol{v}_{\text {основной }}-\boldsymbol{v}_{\text {основной }}+\text { добавка }}{\boldsymbol{v}_{\text {основноㄴ }}}$} & \multirow{2}{*}{$\begin{array}{l}\text { Наблюдаемый } \\
\text { эффект }\end{array}$} \\
\hline Основной & Добавочной & & \\
\hline Фенол & $\begin{array}{l}\text { Хинон } \\
\text { БП } \\
\text { Хинон + БП }\end{array}$ & $\begin{array}{l}0,18 \pm 0,04 \\
0,58 \pm 0,05 \\
0,63 \pm 0,06\end{array}$ & Антагонизм \\
\hline \multirow[t]{2}{*}{ Хинон } & $\begin{array}{l}\text { Фенол } \\
\text { БП } \\
\text { Фенол + БП }\end{array}$ & $\begin{array}{l}0,07 \pm 0,04 \\
0,62 \pm 0,03 \\
0,67 \pm 0,05\end{array}$ & Аддитивность \\
\hline & $\begin{array}{l}\text { Фенол } \\
\text { Хинон } \\
\text { Фенол }+ \text { хинон }\end{array}$ & $\begin{array}{l}-0,09 \pm 0,05 \\
-0,20 \pm 0.04 \\
-0,20 \pm 0,04\end{array}$ & Антагонизм \\
\hline
\end{tabular}

позволяет предполагать, что в обоих случаях действует один и тот же продукт их окисления - оксихинон $\left[{ }^{9,10}\right]$. Это подтверждается хорошим совпадением кривых концентрационной зависимости (рис. 2, 18, 12).

В биосфере и в стоках можно ожидать разное соотношение фенолов и БП. Например, в свежих сланцехимических стоках концентрация фенолов в несколько раз превышает концентрацию БП [11]. Однако через некоторое время ввиду устойчивости БП к окислению (табл. 1), концентрация его может даже превышать таковую у фенолов. Поэтому нами исследовано влияние фенолов на скорость превращения БП при различных соотношениях реагентов (табл. 2). Добавки фенола и хинона ускоряют окислительные превращения БП, причем с ростом доли хинона временной порядок реакции окисления БП увеличивается и приближается к первому, что указывает на усиление роли темневых реакций в исчезновении (окислении) БП. Поскольку скорость окисления хинона на два порядка выше, чем скорость окисления БП, возможно, что продукты окисления хинона индуцируют темневое окисление БП.

Исследование деградации реагентов в тройных смесях свидетельствуют о том, что относительно фенола и БП другие компоненты оказывают антагонистическое действие, т. е. эффекты ингибирования фенола и БП здесь меньше ожидаемых при окислении в бинарных смесях (табл. 3). Явление аддитивности определено нами при совместном окислении хинона с фенолом и БП. Отметим, однако, что некоторыми авторами [12] установлено наличие синергического эффекта при действии пространственно-затрудненных фенолов с хиноном в случае окисления углеводородов только в воздухе, а не в кислороде.

Таким образом, нами установлено, что окисление смесей из фенола, двухатомных фенолов, $n$-бензохинона и БП (или при образовании таких смесей в процессе окисления) сопровождается замедлением деградации фенолов и хинона. При этом хинон, гидрохинон и пирокатехин являются более токсичными, чем исходный фенол. Следовательно, эффективность обезвреживания фенолов и БП в смесях существенно ниже ожидаемого при окислении индивидуальных веществ.

\section{Выводы}

1. Скорости фотоннициированного окисления n-бензохинона, пирокатехина, фенола и бенз (а)пирена существенно различаются. Их соотношение в относительных единицах $300: 35: 30: 1$. 
2. При соокислении фенолов и хинона в бинарных и тройных смесях с канцерогенным бенз(а)пиреном выявляется эффект взаимного ингибирования.

\section{ЛИТЕ РА Т У Р А}

1. Кирсо У. Определение различных фенолов реакцией с 4-аминоантипирином. Нзв. АН ЭССР. Хим. Геол., 1977, т. 26, № 1, с. 22-27.

2. Thielemann, H. Zum Nachweis von p-Benzochinon mit 1-Phenyl-2,3-Dimethyl-4-Aminopyrazolon-(5). - Pharmazie, 1969, Bd. 24, N 8, S. 483-484.

3. Агроскин Л. С. Сравнение яркостей некоторых источников света для ультрафиолетовой микроскопии. - Биофизика, 1957, т. 2, № 4, с. 518-519.

4. Л ейдл е р К. Кинетика органических реакций. М., 1966.

5. Ки рсо У. Э.-Р. Реакционная способность фенолов в процессах окисления. Автореф. дис. докт. хим. н. Черноголовка, 1978.

6. Велдре И. А., Кирсо У. Э. Изменение токсических свойств фенолов в процессе их окисления. - Гиг. и санит., 1976, № 1, с. 20-22.

7. Эм ануэль Н. М., Дени исов Е. Т., М айзус 3. К. Цепные реакции окисления углеводородов в жидкой фазе. М., 1965.

8. Friedel, R. A., Orchin, M. Ultraviolet Spectra of Aromatic Compounds. New York - London, 1951.

9. Bruce, J. M. Light-induced reactions of quinones. - Quart. Rev. 1967, p. $405-424$.

10. Ельц ов А. В., Студдзинский О. П., Гребенкин а В. М. Иницинрованные светом реакции хинонов, - Усп. хим., 1977, № 2, с. 185-227.

11. Велдре И. А., Л ахе Л. А., Ар ро И. Х. О содержании 3,4-бензпирена в сточных водах предприятий сланцевой промышленности. - Гиг. и санит., 1965, № 11, c. $104-105$.

12. Белова Л. Н., Карпухина Г. В., Майзус 3 . К., Розандев Э. Г., Эм ануэль Н. М. Синергизм антиокислительного действия ароматических аминов и фенолов в смесях с акцепторами R'-радикалов - нитроксильными радикалами, хинонами. - Докл. АН СССР, 1976, т. 231, № 2, с. $369-372$.
Ннститут химии
Академии наук Эстонской ССР
Поступила в редакцию $18 /$ IV 1980

\section{SEVTSUK, Uuve KIRSO}

\section{FENOOLIDE, KINOONI JA BENSO(a)PUREENI VASTASTIKUNE MOJU KOOSOKSUDEERIMISEL}

p-bensokinooni, pürokatehhiini, fenooli ja benso(a)püreeni (kaks esimest on nii fenoolid kui ka oksübensooli laguproduktid) fotoinitsieeritud oksüdeerimise kiirused moodustasid artiklis esitatud katsete põhjal suhtarvudes järgmise rea: $300: 35: 30: 1$. Nimetatud ainete koosoksüdeerimisel kaksik- ja kolmiksegudes toimub vastastikune inhibeerimine, mille ulatus oleneb teise komponendi keemilisest struktuurist ja kogusest.

\section{SHEVCHUK, Uuve KIRSO}

\section{THE EFFECT OF COOXIDATION ON PHENOLS, QUINONE AND BENZO(a)PYRENE}

The rates of photoinduced oxidation of $p$-benzoquinone, catechol, phenol and benzo(a) pyrene (the first two are degradation products of phenol) decreases in the order $300: 35: 30: 1$. In the processes of cooxidation of these compounds in binary and tertiary mixtures, inhibition effects were determined, which depend on the chemical structure and amount of the component added. 